\title{
ACERCA DE LOS VALORES RELACIONALES DE LA SUPERPOSICIÓN DEL HABLA
}

\author{
Marek BARAN \\ Universidad de Łódź
}

\begin{abstract}
In the present study we intend to examine the so-called turn-taking model to verify to what extent the different phenomena, which are assigned to it, are changing. We will try to confirm how they change not only with structural qualifications but also with relational values that, according to conversational analysis and postulates of speech ethnography, correspond to interpersonal functions. What is more, we shall demonstrate that overlaps and interruptions are products of the different pragmatic intentions and they cannot be seen only in terms of deviations or transgressions to the system of distribution of parole.
\end{abstract}

\section{A MOdo DE INTRODUCCIÓN}

Con las líneas que siguen, pretendemos acercarnos al así llamado sistema secuencial del habla para comprobar en qué medida distintos fenómenos que se le adscribe se tiñen no solamente de matizaciones estructuradoras, sino también de valores relacionales que, de acuerdo con los postulados del análisis conversacional y de la etnografía del habla, corresponden a las funciones interpersonales. Nuestra perspectiva va a ser esencialmente conversacional porque, tal y como se subraya a menudo en los planteamientos de lingüística interaccional, las conversaciones cotidianas se presentan como una forma prototípica de la interacción humana. Trataremos de demostrar que los solapamientos y las interrupciones son producto de diferentes intencionalidades pragmáticas y que no pueden, por tanto, verse únicamente en términos de "desviaciones" o "transgresiones" al sistema de la distribución de la parole. 


\section{Sistema Secuencial del habla}

El interés por las formas o las técnicas de las que nos servimos para tomar la palabra empieza ya en los años setenta. En numerosas ocasiones suele mencionarse dicha época para indicar los comienzos del mencionado antes análisis conversacional. Habría que darse cuenta de que, aunque aquella época supone realmente un giro importante en los estudios lingüísticos y, en particular, en los acercamientos de índole interaccional, el interés por la forma sigue siendo fuertísimo. Así pues, la coordinación de los llamados turnos de habla se describe básicamente a través de los esquemas formales: los estudiosos tratan de identificar los lugares posibles de transición en los que la alternancia suele producirse; se observan, de igual modo, las técnicas de distribución del habla. De inmediato, habrá que precisar que por turno se entiende hueco estructural rellenado con emisiones informativas que son reconocidas por los interlocutores mediante su atención manifiesta y simultánea. Los turnos están separados por los llamados intervalos silenciosos, normalmente muy breves, los cuales en su duración no coinciden siempre en diferentes comunidades de habla ${ }^{1}$.

El punto de referencia fundamental en los estudios de la alternancia de turnos lo constituye el conocidísimo modelo de turn-taking de Sacks, Schegloff y Jefferson $(1974)^{2}$. Los investigadores mencionados admitieron que la alternancia de participantes en una conversación está orientada por el principio de "un hablante por vez", el cual establece un momento y un espacio conversacional determinado para que los interlocutores procedan comunicativamente. Al esquematizar el modelo de distribución de los turnos conversacionales, los analistas definen unas cuantas reglas. Según estas últimas

1. El cambio de hablante es recurrente o, al menos, se produce. Es decir, una de las características de la conversación es que es dialogal.

2. En general, no habla más de una persona a la vez.

3. Los solapamientos (dos - o más - participantes a la vez) son comunes pero breves.

4. Las transiciones más comunes entre un turno de palabra y el siguiente son las que se producen sin intervalos ni solapamientos, o las que se producen con un breve intervalo.

${ }^{1}$ La distinta duración de los intervalos silenciosos puede ocasionar malentendidos socioculturales (véase, en este sentido, Saville-Troike (1985: 13) o Baran (2014a)).

${ }^{2}$ En lo que se refiere a la lengua francesa, Kerbrat-Orecchioni (1990) en el primer volumen de Les interactions verbales dedica todo un capítulo al sistema de turnos de habla (se trata, en concreto, del capítulo 3: "Le système des tours de parole"). Las cuestiones como "le réglage de l'alternance", así como "les ratés du système des tours" están tratadas de forma detallada.

${ }^{3}$ Las listamos aprovechando la traducción española ofrecida por Tusón Valls (2002: 137). 
5. El orden de los turnos de palabra no es fijo.

6. La duración de los turnos de palabra no es fija, si bien se tiende a un cierto equilibrio.

7. La duración de una conversación no se especifica previamente.

8. Lo que dicen los hablantes no se ha especificado previamente.

9. La distribución de los turnos de palabra no se ha especificado previamente.

10. El número de hablantes puede variar.

11. El discurso puede ser continuo o discontinuo.

12. Existen técnicas para la distribución de los turnos.

13. Se utilizan diferentes unidades formales de construcción de los turnos (una palabra, una frase, una oración, etc.).

14. Existen mecanismos para reparar los errores o las transgresiones en la toma de la palabra.

La toma de turnos está manejada mediante algún tipo de señalización lingüística o no lingüística ${ }^{4}$ de ahí que el hablante deje conocer al interlocutor sus movimientos para que éste pueda tomar la palabra, de forma coordinada, en un momento apropiado para la transición. Los casos en los que la alternancia no sigue el principio anterior se perciben básicamente como transgresiones al sistema, constituyendo violaciones al momento y espacio propio del hablante en curso. Dichas transgresiones se concretizan fundamentalmente en solapamientos e interrupciones y, de acuerdo con los presupuestos claramente etnocéntricos del análisis conversacional, se observan en cantidades estadísticamente despreciables (Baran, 2014a: 229).

Según Cestero Mancera (2000: 140-141), existen dos categorías principales de cambios interruptivos: 1) cambios de hablante con superposición de habla, y 2) cambios de hablante sin superposición de habla. Las tipologías que toman en cuenta la posesión de la palabra abarcan, de igual modo, otros dos grupos fundamentales. Así pues, las alternancias (que, en este caso, funcionan como hiperónimo funcional-denominativo del fenómeno interruptivo) se dividen en:

1) Alternancias propias: son las que se producen una vez finalizado el turno de habla y sin superposición (el cambio de hablante se produce tras la conclusión de mensaje; se supone que de esta forma se cumplen las normas sociales de intercambio);

2) Alternancias impropias: al darse esta modalidad, un conversador toma la palabra sin que haya sido marcado el final del mensaje y turno

${ }^{4}$ El hablante cede la palabra al interlocutor mediante señales prosódicas (terminales entonativas) o cinéticas (mirada, ademanes), dadas en determinados puntos del enunciado, que generalmente coinciden con los límites sintácticos mayores. 
precedente, lo cual supone una ruptura del mecanismo de alternancia de turnos (se amenazan dos principios básicos sobre los que se sustenta una conversación: el de cooperación y el de secuenciación).

Gallardo Paúls (1993: 205) apunta que la cuestión de alternancias que suelen producirse en las conversaciones resulta incompleta si no tomamos en cuenta los casos de habla simultánea. Se trata, de hecho, de los así llamados solapamientos: se dan cuando dos hablantes se autoseleccionan en el mismo lugar de transición o cuando uno se autoselecciona sin que el que tenía la palabra haya finalizado su turno. Para Cordisco (2003: 149), los solapamientos constituyen fundamentalmente simultaneidades ocasionadas por "errores involuntarios" de los interlocutores que tratan de tomar turno en un momento inadecuado. Se trataría, pues, de fenómenos breves y frecuentes que no afectan en mayor grado al transcurso de la conversación ${ }^{6}$.

Como podemos ver, distintas tipologías indican las posibles causas que motivan la aparición de cambios interruptivos. Si seguimos indagando en esta cuestión, descubrimos rápidamente que los primeros estudios dedicados al tema de alternancia de turnos operan con conceptos tales como poder, control o dominancia. Los investigadores como Zimmerman y West $(1975)^{7}$ defendían la influencia de factores y valores sociales como el estatus y el poder, considerando la interrupción como una estrategia de control de la conversación. De ese modo, basándose en la teoría de las características de estatus ${ }^{8}$, se afirmaba que la interrupción es privilegio del interlocutor que aparenta un estatus más alto en la interacción (Cestero Mancera, ibid., p. 142).

\section{SOLAPAMIENTOS E INTERRUPCIONES: INTENCIONALIDADES (SOCIO)PRAGMÁTICAS}

Los enfoques de índole pragmática pusieron en duda las hipótesis así definidas. Teniendo en cuenta distintas intencionalidades de los hablantes, se empezó, por consiguiente, a distinguir entre alternancias impropias: voluntarias e involuntarias. Las primeras, en palabras de Cestero Mancera (ibid., p. 143), "se producen

\footnotetext{
${ }^{5}$ En la terminología anglosajona overlaps. La teoría de la comunicación desarrollada en Polonia se sirve, en este caso, del término nakładki.

${ }^{6}$ Desde esta perspectiva, una interrupción sería una forma marcada de solapamiento, la cual consiste en un intento consciente de capturar el turno.

${ }^{7}$ Véase, a este respecto, Greif (1980).

${ }^{8}$ Véase la denominada Status characteristics theory de Berger, Fisek, Norman y Zelditch (1977).
} 
cuando los conversadores no atienden, conscientemente, las indicaciones de sus interlocutores; no prestan atención al significado de las marcas que se emiten en el turno en marcha". Las segundas, por su parte, "se producen cuando los conversadores no interpretan bien o no reconocen el valor significativo de las marcas que se emiten en el turno en marcha; se trata de anomalías en el sistema de cambio de hablante, fenómenos peculiares en la conversación" (Cestero Mancera, ibid.). Las clasificaciones existentes sugieren, además, hablar de las interrupciones de tipo competitivo (las que, acompañadas de un tono de voz especialmente elevado, tratan de imponerse) y de las interrupciones o turnos colaborativos (cuya finalidad es la de terminar el turno con las mismas palabras que el hablante). El deseo de controlar a los demás no debería, por consiguiente, interpretarse como una motivación principal de los cambios interruptivos. Recurriendo a los conceptos propios de la teoría de la cortesía verbal, parece legítimo sostener que los mecanismos de la toma de turnos (entre ellos, las interrupciones y los solapamientos) se hacen operativos en función de la gestión de las imágenes ${ }^{9}$ que los interlocutores ponen en juego a lo largo de los intercambios comunicativos. No es de descartar que en numerosísimos casos la proyección de una imagen afiliativa ${ }^{10}$ domina sobre el principio de no-interferencia y respeto del territorio ajeno.

Seguramente resultaría interesante comprobar con algunos datos de tipo cuantitativo qué representatividad tienen las modalidades de solapamientos / interrupciones de carácter colaborativo y competitivo. Para eso, nos serviremos de los resultados de análisis llevados a cabo por Cestero Mancera. La investigadora en cuestión había realizado dos estudios cuantitativos $(1994,2000)$ que demostraron que en la conversación cotidiana en lengua española se produce igual número de alternancias propias que impropias. De 1774 alternancias analizadas en la monografía en el año 2000, entre turnos de habla, falsos comienzos, finales simultáneos, y turnos introducidos por un apoyo, 827 eran alternancias impropias $(=47 \%), 25$ fallos de señalización $(=1,4 \%)$ y el resto, 828 , eran alternancias propias, constituyendo así el 46,7\% del total (a excepción de 94 casos de alternancias anómalas, el 5,3\%). Un corpus anterior sobre el que trabajó Cestero Mancera (1994: 95-96) confirma plenamente la misma tendencia: el 43\% de las alternancias analizadas (que fueron 245 en total) son alternancias impropias, las alternancias propias constituyen el $46 \%$ de casos analizados.

${ }^{9}$ Recurrimos, obviamente, al famoso concepto de Goffman (1967), pensando, de igual modo, en el face-work del que hablan Brown y Levinson $(1978,1987)$.

${ }^{10} \mathrm{La}$ que acentúa los valores propios de la cortesía positiva (en el sentido que le otorgan Brown y Levinson, 1978, 1987). 
¿De qué modo deberíamos interpretar dichos datos? No olvidemos que, siguiendo las líneas interpretativas que se postulaban en el marco del modelo secuencial de Sacks, Schegloff y Jefferson (1974), la mitad de las alternancias deberían considerarse "anomalías, transgresiones o violaciones al sistema".

Estamos convencidos de que al analizar el fenómeno de superposición del habla conviene admitir que la apropiación del fluir conversacional (que abarca distintos tipos de solapamientos o interrupciones) surge de una multitud de causas individuales e interaccionales, y no tan solo, como se lo solía explicar en las teorías de poder y control, del deseo de imponerse a los demás. Sin lugar a dudas, los interlocutores, al manejar el sistema de turnos, construyen y afirman ciertas imágenes según características del entorno comunicativo, como también según su propio contexto sociocultural. De ese modo, la noción de imagen social puede examinarse desde las dimensiones de autonomía y afiliación. En otros términos, las convenciones socioculturales (cuyo reflejo, como es de suponer, se deja percibir en la lengua) compartidas por los interlocutores pueden encaminarse hacia la imagen de autonomía, poniendo de relieve los valores como la no-interferencia y el respeto del territorio ajeno, o responder más bien al perfil afiliativo en el que se recalcan características y comportamientos que identifican el individuo con el grupo. En este sentido, las instancias interruptivas pueden también apuntar a la proyección una imagen afiliativa o una imagen desafiliativa. Cuando los comportamientos conversacionales tienden a compartirse o a adscribirse a aquellas características que cohesionan al grupo, podemos hablar de interrupciones afiliativas; las interrupciones desafiliativas se relacionan, por su parte, con los comportamientos que resaltan a un interlocutor de los demás, dando al mismo tiempo una imagen no deseada (desaprobación o rechazo de la imagen consensuada por el resto del grupo (Cordisco, 2003: 152)). Dicha bipartición remite, al menos en parte, a la distinción entre alternancias colaborativas y conflictivas. Al tomar en consideración la modalidad de interrupción afiliativa, de ningún modo puede seguirse con la idea de las instancias interruptivas como anomalías, desviaciones o transgresiones al sistema, como tampoco puede verse en ellas tan solo amenazas a la imagen social del participante. Como subraya Cordisco (ibid., p. 152-154), las interrupciones pueden tensionar o distender el clima socio-emocional del encuentro comunicativo, según se desatienda o se coopere con la imagen que el hablante interrumpido proyecta y a la cual se adhiere. Bajo esta óptica, las interrupciones son además un fenómeno co-producido tanto por el interlocutor que interrumpe como por el interrumpido a través de sus contribuciones comunicativas.

Teniendo en cuenta la cuantificación de las alternancias impropias que se producen en la conversación cotidiana en lengua española podemos suponer que estas últimas en su mayoría son justificadas y explicables desde el punto de 
vista del perfil comunicativo dominante. Nos servimos, en este momento, de una de las nociones clave de la lingüística interaccional contemporánea, la cual está estrechamente vinculada con la teoría de ethos comunicativo. Esta última nace de la ambición de dar cuenta de sistema de valores y preferencias colectivas que viene reflejándose en la realidad de los intercambios verbales. Dicho supuesto metodológico-interpretativo, fundamentado básicamente en la propuesta de Kerbrat-Orecchioni (1994, 2005), admite que reglas, normas, rutinas conversacionales, usos típicos propios de los comportamientos discursivos, pueden interpretarse como una conjunción de hechos lingüísticos que obedecen a una coherencia profunda. La teoría del ethos comunicativo, junto con la etnografía de la comunicación o algunos aportes de los análisis contrastivos de los actos de habla, acentúan el papel de las convenciones o condicionamientos sociales preestablecidos que dominan en unas determinadas comunidades de habla. Sin rechazar la importancia de los elementos situacionales y los que están estrechamente vinculados con el entorno contextual, puede sostenerse, por tanto, que la negociación de roles que se lleva a cabo en la interacción se relaciona también con un proceso más general de adhesión a un determinado posicionamiento de carácter etológico. El ethos comunicativo, asociado con determinadas normas de comunicación / interacción compartidas por los miembros de una comunidad de habla, puede perfilarse mediante la observación de unos cuantos ejes que podrían considerarse categorías fundadoras de una eventual tipología de "ethnolectos conversacionales" ${ }^{11}$. Al tomar en cuenta el hecho de que las comunidades de habla hispana se sitúen fundamentalmente del lado de las Positive Politeness Cultures (Brown y Levinson, 1987), en las que destacan elementos tales como: la cercanía emotiva entre los interlocutores, la intensificación a nivel de la relación interpersonal y la proximidad / solidaridad concebidas en términos de una convención sociocultural, entenderemos mejor que las instancias interruptivas presentan básicamente un carácter cooperativo. Los solapamientos y las interrupciones, frecuentes en las conversaciones entre los españoles y, normalmente, breves, no quebrantan, pues, los derechos de los interlocutores, sino más bien, en un número considerable de casos, suponen un cambio de valores en la conducta comunicativa. Demostrar interés por la emisión del hablante vale más que respetar las normas de sucesión de toma de turnos $^{12}$.

${ }^{11}$ Para más detalle sobre la teoría de ethos comunicativo junto con sus parámetros tipológicos, véase Baran (2010).

${ }^{12}$ Lo confirman, además, los análisis cuantitativo-cualitativos efectuados en otros ámbitos de habla hispana por Cordisco (2003). 


\section{A MOdo de CONCLUSIÓN}

Como acabamos de demostrar, las interrupciones no deberían verse como un acto intrínsecamente amenazante (Face-Threatening Act [FTA] en la terminología de Brown y Levinson, 1987). Los condicionamientos contextuales y situacionales, junto con todo el abanico de factores derivados del ethos comunicativo dominante, pueden llevar a interpretaciones pragmáticas diferentes. La instancia interruptiva pertenece, por consiguiente, a una amplia clase de estrategias (socio)pragmáticas cuya finalidad es básicamente intensificadora (pensamos, obviamente, en la intensificación que se da a nivel de las relaciones interpersonales que se van estableciendo entre los interlocutores).

Desde una perspectiva más global, afirmaríamos también que distintos mecanismos que se producen dentro de los que conocemos como superposición del habla, dan perfectamente cuenta de la subjetividad ${ }^{13}$ de los usuarios de la lengua respecto a la planificación y la interpretación del discurso. La observación de la toma de posición de los hablantes, la cual puede asociarse con el nivel de involucramiento ${ }^{14}$ en la escena discursiva, debería constituir un paso obligado en cualquier intento de análisis funcional. Estamos plenamente convencidos de que a lo largo de todo tipo de intercambios comunicativos las acciones textuales (o las de estructuración discursiva) se entrelazan siempre con las actitudes de índole interpersonal. La lingüística interaccional se nos presenta, por consiguiente, como un marco metodológico-interpretativo adecuado para el análisis de valores relacionales de diferentes formas, estrategias o mecanismos lingüísticos.

\section{Referencias bibliográficas}

BARAN, Marek (2010), Emotividad y convención sociopragmática. Una contribución al estudio del ethos comunicativo de la comunidad hispanohablante peninsular, Łódź, Wydawnictwo Uniwersytetu Łódzkiego.

BARAN, Marek (2014a), «El parámetro de verbosidad en la tipificación sociopragmática de los perfiles comunicativos », in Ensayos de Lingüistica Hispánica (J. M. Santos Rovira éd.), Lisboa, Universidade de Lisboa / Sinapis Editores, pp. 229-244.

BARAN, Marek (2014b), « La subjetivización y las dinámicas interaccionales », Studia Romanica Posnaniensia, vol. 41, n 1, pp. 3-16.

${ }^{13}$ Para más detalle sobre las cuestiones de subjetividad y subjetivización lingüísticas véase Company Company (2004) o Baran (2014b).

${ }^{14}$ Concepto que corresponde en líneas generales a la noción de involvement desarrollada en las corrientes interaccionales, entre otros, por Daneš (1994) y Tannen (1989). 
BARAN, Marek (2015), «Armonía y contraste en los sistemas de alternancia de turnos de habla », in Armonía y contrastes. Estudios sobre la variación dialectal, histórica y sociolingüística de español (J. M. Santos Rovira éd.), Lugo, Editorial Axac, pp. 289-298.

BERGER, Joseph, FISEK, M. Hamit, NORMAN, Robert Z., ZELDITCH Jr., Morris (1977), Status Characteristics and Social Interaction: An Expectation States Approach, New York, Elsevier.

BROWN, Penelope, LEVINSON, Stephen C. (1978), « Universals in language usage: Politeness phenomena », in Questions and Politeness. Strategies in Social Interaction (E. N. Goody éd.), Cambridge, Cambridge University Press, pp. 56-289.

BROWN, Penelope, LEVINSON, Stephen C. (1987), Politeness. Some universals in language usage, Cambridge, Cambridge University Press.

CESTERO MANCERA, Ana María (1994), «Intercambio de turnos de habla en la conversación en lengua española », Revista Española de Lingüística, n 24/1, pp. 77-99.

CESTERO MANCERA, Ana María (2000), El intercambio de turnos de habla en la conversación (análisis sociolingüístico), Alcalá de Henares, Servicio de Publicaciones de la Universidad de Alcalá de Henares.

COMPANY COMPANY, Concepción (2004), « Gramaticalización por subjetivización como prescindibilidad de la sintaxis », Nueva Revista de Filología Hispánica, vol. LII, n 1, pp. 1-27.

CORDISCO, Ariel (2003), «Afiliación y desafiliación: contexto sociocultural en el análisis de la interrupción y de sus consecuencias sociales en la interacción », in Actas del Primer Coloquio del Programa EDICE. La perspectiva no etnocentrista de la cortesía: identidad sociocultural de las comunidades hispanohablantes (D. Bravo éd.), Stockholm, Stockholms Universitet, pp. 149-163.

DANEŠ, František (1994), « Involvement with language and in language », Journal of Pragmatics, vol. 22, pp. 251-264.

GALLARDO PAÚLS, Beatriz (1993), « La transición entre turnos conversacionales: silencios, solapamientos e interrupciones », Contextos, $\mathrm{n}^{\circ} \mathrm{XI} / 21-22$, pp. 189-220.

GOFFMAN, Erving (1967), Interaction Ritual: Essays on Face-to-Face Behavior, New York, Doubleday.

GREIF, Esther Blank (1980), « Sex differences in parent-child conversations », Women's Studies International Quarterly, vol. 3, n 2-3, pp. 253-258.

KERBRAT-ORECCHIONI, Catherine (1990), Les interactions verbales. Tome I, Paris, Armand Colin.

KERBRAT-ORECCHIONI, Catherine (1994), Les interactions verbales. Tome III, Paris, Armand Colin.

KERBRAT-ORECCHIONI, Catherine (2005), Le discours en interaction, Paris, Armand Colin.

SACKS, Harvey, SCHEGLOFF, Emanuel A., JEFFERSON, Gail (1974), « The Simplest Systematics for the Organization of Turn-Taking in Conversation », Language, vol. 50, $\mathrm{n}^{\circ}$ 4, pp. 696-731.

SAVILLE-TROIKE, Muriel (1985), «The place of silence in an integrated theory of communication », in Perspectives on silence (D. Tannen, M. Saville-Troike éds), Norwood, Ablex Publishing Corporation, pp. 3-18. 
TANNEN, Deborah (1989), Talking voices: Repetition, dialogue, and imagery in conversational discourse, Cambridge, Cambridge University Press.

TUSÓN VALLS, Amparo (2002), «El análisis de la conversación: entre la estructura y el sentido », Estudios de Sociolingüística, 3(1), pp. 133-153.

ZIMMERMAN, Don H., WEST, Candace (1975), "Sex roles, interruptions and silences in conversation ", in Language and Sex, difference and dominance (B. Thorne, N. Henley éds), Rowley, MA, Newbury House, pp. 105-129. 